Weir, S., Samnaliev, M., Kuo, T.-C., Tierney, T. S., Walleser Autiero, S., Taylor, R. S. and Schrag, A. (2018) Short- and long-term cost and utilization of health care resources in Parkinson's disease in the UK. Movement Disorders, 33(6), pp. 974981. (doi: $10.1002 / \mathrm{mds} .27302)$.

There may be differences between this version and the published version. You are advised to consult the publisher's version if you wish to cite from it.

This is the peer reviewed version of the following article:

Weir, S., Samnaliev, M., Kuo, T.-C., Tierney, T. S., Walleser Autiero, S., Taylor, R. S. and Schrag, A. (2018) Short- and long-term cost and utilization of health care resources in Parkinson's disease in the UK. Movement Disorders, 33(6), pp. 974981, which has been published in final form at $10.1002 / \mathrm{mds} .27302$. This article may be used for non-commercial purposes in accordance with Wiley Terms and Conditions for Self-Archiving.

http://eprints.gla.ac.uk/193201/

Deposited on: 15 August 2019

Enlighten - Research publications by members of the University of Glasgow http://eprints.gla.ac.uk 


\section{Short- and long-term cost and utilization of health care resources in Parkinson's disease in the UK}

Sharada Weir, DPhil ${ }^{1,2,}{ }^{*}$, Mihail Samnaliev, PhD ${ }^{1,3}$, Tzu-Chun Kuo, PhD ${ }^{1}$, Travis S. Tierney, MD, DPhil ${ }^{4}$, Silke Walleser Autiero, $\mathrm{MPH}^{5}$, Rod S Taylor, $\mathrm{PhD}^{6}$, Anette Schrag, $\mathrm{MD}^{7}$

1. PHMR, LLC, London, UK

2. Institute for Mental Health Policy Research, Centre for Addiction and Mental Health, Toronto, CA

3. Children's Hospital Boston, Harvard Medical School, Boston, US

4. Brain Institute at Nicklaus Children's Hospital, University of Miami Miller School of Medicine, Miami, US

5. Medtronic International Trading Sàrl, Tolochenaz, $\mathrm{CH}$

6. Institute of Health Research, University of Exeter Medical School, Exeter, UK

7. UCL Institute of Neurology, London, UK

*Address for correspondence: Sharada Weir, DPhil, PHMR, Ltd., Bldg D, Berkeley Works, Berkley Grove, London, NW1 8XY, United Kingdom; E-mail: sharadaweir@phmr.com; Tel: 011-44-208-3652185.

Words: 3,662

Running title: Costs of treating Parkinson's in the UK

Key words: Parkinson's disease; Cost-of-illness; Long term follow up; Clinical Practice Research Datalink (CPRD); Hospital Episode Statistics (HES).

Disclosures: SWA was employed by Medtronic International Trading Sàrl, Switzerland. SW, MS and TCK received consulting fees from PHMR, LLC, who were engaged by Medtronic to oversee the project. AS was supported by the National Institute for Health Research University College London Hospitals Biomedical Research Centre. RST and AS received consulting fees from Medtronic as advisors to the project. TT had no competing interests associated with this work.

Funding agencies: This study was sponsored by Medtronic International Trading Sàrl, Switzerland, with the remit to provide data on the direct costs of health care attributable to Parkinson's disease in the short and long-term. No Medtronic products are mentioned in this article and the sponsors did not direct the study design or conduct. 


\section{Abstract}

Background. There is currently no robust long-term data on costs of treating patients with Parkinson's disease (PD).

Objectives. To report levels of healthcare utilization and associated costs in the 10 years after diagnosis among PD patients in the United Kingdom (UK).

Methods. We undertook a retrospective, population-based cohort study using linked data from the UK Clinical Practice Research Datalink (CPRD) and Hospital Episode Statistics (HES) databases. Total healthcare costs of PD patients were compared to those of a control group of patients without PD selected using 1:1 propensity score matching based on age, sex, and comorbidity.

Results. Between 1994 and 2013, 7,271 PD patients who met study inclusion criteria were identified in linked CPRD-HES; 7,060 were matched with controls. The mean annual healthcare cost difference (at 2013 costs) between PD patients and controls was $£ 2,471$ (US\$3,716) per patient in the first year post-diagnosis $(P<0.001)$, increasing to $£ 4,004(U S \$ 6,021)$ per patient $(P<0.001)$ at 10 years following diagnosis due to higher levels of use across all categories healthcare utilization. Costs in patients with markers of advanced PD (i.e., presence of Levodopa Equivalent Daily Dose > 1,100mg, dyskinesias, falls, dementia, psychosis, hospital admission primarily due to PD, or nursing home placement) were on average higher by $f 1,069$ (US\$1,608) per patient than those with PD without these markers.

Conclusions. This study provides comprehensive estimates of healthcare costs in PD patients based on routinely collected data. Healthcare costs attributable to PD increase in the year following diagnosis and are higher for patients with indicators of advanced disease. 


\section{Introduction}

Parkinson's disease (PD) affects an estimated 1\% of people ages 65 and older in the industrialized nations. ${ }^{1}$ The impact of PD on quality of life has been well-documented. ${ }^{1-9}$ Yet little is known about real-world healthcare resource use and cost-of-illness in early and advanced PD. Most prior research has been based on patients enrolled in clinical trials, which are likely to be unrepresentative of the overall population of patients with PD, or are based on relatively small cross-sectional samples of patients. In addition, most studies rely on patient-report of health care use, and are often conducted over a short follow-up period which does not permit calculation of annual changes with disease progression. ${ }^{10-13}$ Long term follow-up data are lacking, and a combined analysis of primary care and hospital records has not been previously attempted in PD. Long-term data on real-life healthcare resource utilization and cost-of-illness are needed to better understand and plan the provision of health care for advancing disease and allow for accurate costeffectiveness analyses and health care decision-making.

The aim of this study was to undertake an assessment of the levels healthcare utilisation and associated costs in the 10 years after diagnosis in a large sample of PD patients in the United Kingdom (UK).

\section{Methods}

\section{Study design}

This study employed a retrospective cohort design using the linked UK databases for primary care and hospital care provision: the Hospital Episode Statistics (HES) database and UK Clinical Practice Research Datalink (CPRD). Costs were estimated using a health system perspective and included direct medical resource use only. Other costs, such as out-of-pocket expenditures by patients, privately-insured spending, and costs of informal and formal caregiving, were not captured. Approval for this study was granted by the Independent Scientific Advisory Committee for Medicines and Healthcare products Regulatory Agency on May 15, 2015 (ISAC Protocol 14-234Mn).

The study period was April 1, 1993 to March 31, 2013. To ensure that patients were newly diagnosed, we excluded patients whose records did not contain a period of at least 12 months prior to the index date (diagnosis of PD or first antiparkinsonian medication prescription). A minimum of 12 months of follow-up data was also required to calculate costs following index diagnosis. We therefore obtained linked HES-CPRD data from April 1, 1992 through March 31, 2014. 


\section{Setting and data sources}

CPRD included detailed primary care medical records for about 5.5 million registered patients from approximately 590 general practices covering $8 \%$ of the UK population. The patient population captured in the database has been shown to be representative of the demographic breakdown of the UK population and the quality and completeness of the data have been well-documented for the CPRD's precursor (incorporated into CPRD), the General Practice Research Database (GPRD). ${ }^{14-}$

${ }^{19}$ Linkage to HES was possible for patients registered with practices in England that use the Vision software system for electronic medical records and have opted in to the data linkage scheme. This amounts to approximately half of patients in the CPRD primary care database. Hospital data on the length, type, reasons and current diagnoses for all National Health Service (NHS) inpatient hospital admissions, accident and emergency (A\&E) visits for those who were admitted to hospital or who were referred to $A \& E$ from their general practice (GP) (excluding self-referrals to A\&E who were not admitted to hospital), and outpatient clinic attendances (from 2003 onwards) were captured regardless of private vs. government payer or geographic residency of the patient. ${ }^{20}$

GPRD data have been used to answer a wide range of health care quality and resource utilization questions, including several studies of PD. ${ }^{12-16}$ To date, no studies using the linked CPRD-HES database have explored Parkinson's disease. Our study population consisted of patients who had data in the CPRD-HES linked datasets and who met all study criteria (described below).

\section{Selection of cases}

We included all patients aged 30 years and older who were newly diagnosed with PD during the study period. Following previous publications, ${ }^{21-26}$ diagnosis of PD was identified using Read codes for PD (see appendix) in the CPRD-GOLD database or International Classification of Disease (ICD)-10 code "G20.X (Parkinson's disease)" in the HES database and at least two prescriptions of antiparkinsonian medication. Prior research has used medical records data to validate that this method correctly identifies $90 \%$ of cases. ${ }^{27}$

Patients with diagnosis codes for secondary Parkinsonism or Parkinson-Plus syndromes at any point in their health record and patients with evidence of exposure to agents known to produce parkinsonian syndromes were excluded. ${ }^{28} \mathrm{~A}$ complete list of diagnosis and medication codes used are included in the appendix.

\section{Selection of controls}

Controls were drawn from the population of adults $\geq 30$ years old who did not have diagnosis codes indicating primary or secondary Parkinsonism at any time during the study period and who had never received prescriptions for drugs to treat PD or drugs known to produce parkinsonism 
syndromes. In line with the minimum data requirement for cases of one year pre-diagnosis and one year post-diagnosis, potential controls were required to have at least two years of eligibility during the study period. Initially, four potential controls subjects were matched to each case based on sex, birth year (+/- 5 years), and general practice where the patient was registered.

In order to account for possible differences in comorbidities between cases and controls we used propensity score matching without replacement from among the full set of initially selected potential control subjects. ${ }^{29,30}$ The propensity score was based on logistic regression modelling the probability of having a PD diagnosis as a function of age, sex, and baseline comorbidity (using all comorbid conditions in the Charlson Comorbidity Index (CCl) with the exception of dementia as this is a possible clinical feature of PD). Controls were selected using the greedy matching algorithm based on a 5->1 digit match, where cases and controls are first matched on the 5th digit of propensity score, and if no matches are found, on the 4th, 3rd, 2nd and 1st digit. ${ }^{29}$ Controls were matched with cases after being assigned a pseudo-diagnosis date, ensuring comparability at the index date. However, they were not matched on length of follow up.

\section{Assessment of health care utilization and costs}

Healthcare utilization was categorized by setting/category of service and calculated for 12-month periods from index date for each category: antiparkinsonian medications (number of prescriptions, categorized by product, strength and formulation) and other medications (number of prescriptions, categorized by 6-digit BNF code), number of primary care episodes, number of outpatient episodes, number of inpatient episodes, and A\&E visits. Results are provided for years 1 to 10 from diagnosis.

We used a matched control cost-of-illness (COI) approach ${ }^{31-33}$ to estimate total healthcare costs and assigned unit costs following standard practice for $\mathrm{COI}$ and cost effectiveness research (detailed in the online appendix to this paper). ${ }^{34-43}$ Consistent with other studies of resource utilization, ${ }^{44}$ we estimated total annual costs per patient for each available year of follow up. To account for inflation and variations in pricing over time, 2013 unit costs were applied to all years. ${ }^{45-49}$ Total costs incorporate direct (e.g., medical staff), indirect (e.g., administration and security staff) and overhead (e.g., facilities) costs. In the summary, costs were converted to 2013 US dollars for comparability with international studies using the UK pound to US dollar 2013 yearly average exchange rate published by the US Internal Revenue Service ( 1 UK pound=1.5038 US dollars). More details on the methods used to estimate costs for each category of service (e.g., inpatient care, primary care, etc.) are included with the appendix.

\section{Data analysis}

Costs (C) attributable to PD were estimated by comparing PD patient total medical costs with those of the matched control cohort as follows: 


$$
\mathrm{C}_{\text {net }}=\mathrm{C}_{\text {case }}-\mathrm{C}_{\text {control, }} \text { with variance } \operatorname{Var}\left(\mathrm{C}_{\text {net }}\right)=\operatorname{Var}\left(\mathrm{C}_{\text {case }}\right)+\operatorname{Var}\left(\mathrm{C}_{\text {control }}\right) \text {. }
$$

This approach of using total medical costs among PD patients (as opposed to the costs of PD only) avoids inaccuracies and the practical challenges of assigning each service/procedure to a PD diagnosis. Another benefit of this approach is that it incorporates costs of Parkinson-related comorbidities and events (e.g., falls related to PD) that might not be assigned a PD diagnosis code but are nonetheless attributable to PD directly (proximate cause) or indirectly (ultimate or distal cause).

Subgroup analyses were undertaken to compare costs for patients with early versus advanced disease. Although there is no definitive consensus in prior research on indicators of PD progression, we used a set of indicators of advanced PD similar to those that have been utilized in prior research relying on medical records data, ${ }^{50}$ which also correspond to the indicators of advanced PD in postmortem studies. ${ }^{51}$

We considered a patient to have moved into a more advanced stage of PD if they either (a) had evidence of the development of motor complications or (b) had received an additional indicative Read or ICD code or (c) experienced a sentinel event, as follows:

a) Evidence or likelihood of motor complications (e.g., dyskinesia) was defined to include a diagnosis code indicating dyskinesia, a prescription for Amantadine (rarely used in patients without dyskinesia), or reaching or exceeding a total Levodopa Equivalent Daily Dose $\left(\right.$ LEDD) ${ }^{52}$ equal to or greater than $1100 \mathrm{mg}$ - which corresponds to approximate mean baseline levels of LEDD among cases and controls with advanced PD and motor complications in clinical trials of Deep Brain Stimulation (DBS) for PD ${ }^{53}$ - for a minimum of three consecutive months in two consecutive years (to account for overprescribing during medication changes in one year).

b) Additional indicative Read codes that may indicate disease progression included codes for falls, dementia or psychosis. We included only codes that were recorded more than 2 years following diagnosis of PD in order to exclude pre-existing, non-PD related diagnoses or causes.

c) Sentinel events included evidence of first use of a wheelchair, inpatient admission primarily due to PD, or a move into a nursing home, each occurring more than 2 years after diagnosis.

All analyses were conducted using SAS software, Version 9.3 for Windows. Differences in the matched groups were evaluated using chi-square tests for categorical variables and non-parametric tests (based on 1,000 bootstrap replicates) for mean costs. Statistical significance of independent variables in each model were evaluated at the alpha $<0.05$ and $<0.01$ levels. All analyses were 
adjusted for the length of follow-up. Sub-analyses were also conducted to estimate average annual costs by year of available follow up for cases and controls.

\section{Results}

\section{Baseline characteristics and follow up}

In total, there were 7,271 PD patients with linked CPRD-HES data over the study intake period. Of these, matched controls could be identified for 7,0606 . The control group was similar in terms of age, sex and comorbid conditions (Table 1).

All cases and matched controls had at least one year of complete follow up after the index date. In each subsequent year, more cases than controls were lost to follow up. At the end of 10 years following diagnosis, 782 PD patients (11.1\%) remained in the data versus 3,158 of the matched controls (44.7\%). On average PD patients had 4.9 years (standard deviation (SD) 3.4) of follow up data available, compared with 8.7 years (SD 4.3) for controls. Costs were summarized for cases and controls by years of follow up (available in the online appendix).

\section{Health resource utilization and costs: all patients}

Health care utilization. Parkinson's patients used, on average, more healthcare resources than matched controls in each year following diagnosis. Compared with age-, sex- and comorbiditymatched controls, on average PD patients had nearly twice as many primary care events (68.6 vs. 37.1 ) and inpatient hospital stays (0.7 vs. 0.4$)$, double the number of prescriptions for non-PD medications ( 11.3 vs. 5.6), more than twice the rate of $A \& E$ visits ( 0.7 vs. 0.3 ), and almost three times as many hospital outpatient visits (Table 2).

Costs by type of health care utilization. Over up to 10 years of follow up, average cost of health care utilization in PD patients was $£ 5,022$ (SD $£ 4,058$ ) per year, compared with $£ 2,001$ (SD $£ 2,000$ ) per year in matched controls. Mean costs were significantly higher across all categories of health care utilization, including primary care (by a factor of 1.9), inpatient stays (by a factor of 2.5), A\&E attendances (by a factor of 2.7), selected non-PD medications (by a factor of 3.0) and outpatient visits (by a factor of 8.5 ) (Table 2 ).

Overall, primary care episodes accounted for $46.9 \%$ of the total costs for PD patients, inpatient stays for $30.2 \%$, non-PD medications for $4.4 \%$, PD medications for $7.7 \%$, and outpatient visits for 9.8\%. The largest category, primary care, included six different types of encounter: clinic (mean: 1.7 encounters/year; SD:3.7), telephone (mean:1.7; SD:3.9), non-standard time or location (including out-of-hours, night visits, home/residence visits, and emergency; mean:2.1; SD:4.0), surgery 
(mean:12.5; SD:11.8), administrative (mean:29.0, SD:27.7), and other (which included encounters such as 'medicine management', 'repeat issue' and 'third party consultation'; mean:21.6; SD:16.7).

For comparability with prior studies that used patient-reported survey data, ${ }^{10-13}$ we conducted a sensitivity analysis of the impact on total cost of including only direct patient contacts and prescriptions (i.e., excluding administrative events and other encounters from the primary care cost estimates). In that case, average total cost of health care utilization in PD patients was $£ 3,382$ (SD $£ 3,613$ ) per year, compared with $£ 1,192$ (SD $£ 1,524$ ) per year in matched controls. In this case, primary care constitutes $21.1 \%$ of total direct health expenditures on PD patients.

Time trends. Average costs were $£ 4,050$ (SD $£ 4,326$ ) among PD patients in the first year postdiagnosis and $£ 1,580$ (SD $£ 2,555$ ) among controls in the same time period, reflecting higher costs among PD patients for all types of care, including primary care, hospitalizations, and prescription drugs. The mean annual cost difference between PD patients and controls was $f 2,471(P<0.001)$ in the first year post-diagnosis, rising to $f 4,004(P<0.001)$ at year 10 (Figure 1 ).

\section{Health resource utilization and costs: patients with advanced disease}

Out of the 7,060 patients, 3,958 (56.1\%) developed advanced disease at any point during the 10year follow-up period. The percentage of patients with new indicators of advanced disease increased from $2 \%$ at one year post-index PD diagnosis date to $49 \%$ among those with 10 years of follow up data. Utilization among patients who developed advanced disease was significantly higher, annually, for inpatient stays, accident and emergency visits, primary care, and non-PD medications, but did not differ for outpatient hospital care or anti-PD medications. On average, during the 10 years of follow up, patients with advanced PD had annual costs of $£ 5,491$ (SD $£ 3,602$ ) compared with $£ 4,422$ (SD $£ 4,498$ ) among those without advanced disease (Table 3). All expenditure categories were significantly higher among advanced PD patients with the exceptions of outpatient hospital encounters and non-PD medications.

\section{Health resource utilization and costs: patients with dementia}

Dementia was twice as likely to be recorded among PD patients than control subjects ( $28.3 \%$ vs $14.1 \% ; \mathrm{P}<0.001$ ). During the 10 years of follow up, PD patients with dementia recorded at any point during follow-up had higher mean costs than those without dementia $(£ 5,649$ vs. $£ 4,773 ; P<$ 0.001), with the additional costs due to dementia at any point during follow up being higher among $P D$ versus controls ( $£ 876$ vs $£ 560 ; P=0.022$ ) (Figure 2 ). 


\section{Discussion}

This is the first study that reports linked primary and secondary care data in the United Kingdom to evaluate short- and long-term costs of treating patients with Parkinson's disease over time. We took a net cost approach to consider all direct medical costs that may be either immediately attributable to PD (proximate cause) or related to a PD diagnosis (ultimate cause). Mean costs attributable to PD rose steadily from $£ 2,471(U S \$ 3,716)$ per patient higher in the first year following diagnosis up to $£ 4,004$ (US\$6,021) per patient in year 10 .

Direct comparison to prior studies is difficult, due to different methodologies such as estimating healthcare utilization using patient or physician survey data or comparison with control populations and differences in reporting such as total costs. ${ }^{10-13}$ In addition, most studies did not distinguish between patients with early or more advanced disease. The overall costs of healthcare we attributed to PD alone of $£ 3,021(\$ 4,543)$ were slightly lower than those in a US study using similar methods (annual average over five years $\$ 5,362$, after inflating to 2013 dollars using the Medical Care component of the US Consumer Price Index)..$^{50}$ However, they were higher than the average direct healthcare costs in patients with PD in a survey-based UK study, with a total health care cost of $£ 3,382$ excluding administrative costs in this study compared to $£ 2,836$ in the survey-based study (assuming 3.3\% growth per year mirroring general UK inflation in the period between the studies). ${ }^{12}$ The overall total annual direct health care cost of $£ 5,022$ in patients with PD in this study is similar to that estimated for patients with dementia in the UK in 2013 ( $f 5,285$ per person). ${ }^{54}$

After excluding non-PD specific medications for comparability with prior research, we found approximately the same proportion of formal care costs attributable to PD for hospitalizations (31.3\%) as previously reported in the UK. ${ }^{12}$ However, the costs of antiparkinsonian medication in the present study were a relatively small contributor (13.5\%) to direct cost, in contrast to other studies which attributed approximately $20-30 \%$ of costs to drugs. ${ }^{12,55,56}$ We found higher primary and outpatient hospital care costs (54.1\% of all costs) than McCrone and colleagues who, using a standard NHS survey instrument to assess healthcare utilization, attributed only $49.0 \%$ of costs to primary care, outpatient hospital and all other healthcare encounters combined. ${ }^{12}$ This difference may be due to problems with accurate recall in patient surveys and the relatively high rate of administrative and other primary care encounters that we found. Of particular note, accessing patient medical records allowed us to capture a range of administrative encounters in primary care (e.g., recording patient data from letters sent to GPs by specialists to whom they have referred the patient for care) that cannot be captured using patient surveys.

This study concentrated on the direct healthcare costs to the healthcare system, and did not capture social services, lost earnings or informal care costs. Whilst these are more difficult to estimate accurately, those costs represent a large proportion of costs attributable to PD, particularly in older patients. ${ }^{11,12,50,57}$ In one study, in patients $<65$ years costs to the NHS 
represented $65 \%$ of the overall costs, whereas in older patients costs to the NHS comprised only $21 \%$ and were dwarfed by social services costs and private expenditure. ${ }^{58} \mathrm{~A}$ recent report estimated the cost of lost earnings earnings and out-of-pocket expenditures by patients at $£ 16,582$ per year. ${ }^{59}$ Therefore, if these informal care costs as well as formal social care are considered together with the direct health care costs calculated here, the overall cost of PD for society is estimated to be at least $€ 25,000$ per person with PD.

This study has some some limitations. Firstly, due to the limitations of the data available, our estimates of the costs attributable to PD from HES are likely to be conservative because HES outpatient data were not available prior to 2003, and A\&E self-referrals that did not result in inpatient admission were not captured in our data. On the other hand, we may have overestimated costs from primary care as we used an inclusive approach to calculate primary care costs, comprising consultations, administrative and other costs. Whilst this has the advantage of including all costs, it is likely to overestimate the costs when several events took place at the same time. However, even when restricting the primary care costs to consultations, the overall annual costs for PD were still $£ 3,382$ compared to $£ 1,192$ in controls. Thirdly, we may have overestimated the utilization and costs of antiparkinsonian medications. Prescription data in medical records indicate the physician's intention, but do not directly reveal any information regarding patient compliance with prescribed therapies including whether prescriptions were filled. On the other hand, some costly PD medications were not available early in our study period or went out of patent protection during that period, and the inclusion of patients diagnosed prior to the introduction of these therapies or after their patent expiry date may have underestimated mean medication costs that would apply to particular years. Fourthly, in each year, more cases than control subjects were lost to follow up. If this was due to higher mortality, then direct medical costs in PD are curtailed. However, given the increasing disability with longer disease duration it is likely that more PD patients transferred into skilled nursing or long term care facilities. Whilst our data do not provide sufficient information to determine the reasons for lost follow up, costs for these patients are likely to be considerably higher than for matched controls leading to an underestimation of PD-related costs.

In terms of calculating costs associated with markers of advanced disease, these data should be treated as estimates. We did not have data necessary to directly characterize disease progression (e.g., Unified Parkinson's Disease Rating Scale (UPDRS) score, Hoehn \& Yahr stage) as these are rarely captured in medical records, and we used proxies to indicate advanced disease. Similarly, the costs of associated dementia are estimates as they are based on recorded diagnosis of dementia rather than cognitive assessments. For both categories, summary costs for increased healthcare utilization was used as onset is difficult to determine. Therefore, the results of these sub-analyses should be interpreted cautiously. 
The costs reported here do not exactly reflect costs to the NHS of caring for PD patients since primary care physicians are paid a capitated fee per patient that does not take into account disease burden. Given this, the net costs of PD to the NHS would be the costs of all encounters except primary care, since costs for cases and controls would be identical there. It is however important to take a health system perspective, rather than simply estimating costs to the NHS that do not fully reflect resource utilization.

This study is unique in using linked primary and secondary care medical records data to evaluate costs of treating patients with Parkinson's disease in the UK. Our use of administrative data permitted an unusually long study period, with some patients followed for more than 10 years. Our estimates are clearly conservative, in total, since we were not able to include nursing home, social services, lost productivity, or informal care costs. However, we believe that the choice of using a case-control net cost analysis enabled us to provide more complete and accurate estimates of direct medical costs attributable to PD than have previously been reported for the UK. Our method allowed us to highlight the gap between PD patients and age-, sex- and comorbidity-matched controls without PD and show that this gap rises as PD progresses over time.

This study aimed to advance our understanding of health care resource use and costs of PD, critical for resource allocation decisions in this area. Further research, using data on social care such as nursing home costs, informal and indirect care costs, is needed to obtain a more complete picture of how health care resource utilization changes with advancing PD. This would strengthen analyses of the long-term cost effectiveness of available therapies, such as deep brain stimulation, and of drugs that potentially delay disease progression, to delay or reverse the onset of debilitating effects of the disease and its treatment and would help to inform the development of clinical guidelines and policy decisions. 


\section{Acknowledgements}

Funding provided by the Neuromodulation Reimbursement and Health Economics Function, Medtronic International Trading Sàrl, Switzerland. Funke Stauble provided invaluable advice and encouragement for this study.

This study was based in part on data from the Clinical Practice Research Datalink obtained under license from the UK Medicines and Healthcare products Regulatory Agency. However, the interpretation and conclusions contained in this study are those of the author/s alone.

Author's roles: 1) Research project: A. Conception, B. Organization, C. Execution; 2) Statistical Analysis: A. Design, B. Execution, C. Review and Critique; 3) Manuscript: A. Writing of the first draft, B. Review and Critique

S.W.A.: 1A, 2C, 3B

T-C.K.: 1B, 1C, 2A, 2B, 3A, 3B

M.S.: 1B, 1C, 2A, 2B, 3A, 3B

R.S.T.: 1B, 2A, 2C, 3B

T.T.: 1B, 2C, 3B

A.S.: $1 \mathrm{~A}, 1 \mathrm{~B}, 2 \mathrm{~A}, 2 \mathrm{C}, 3 \mathrm{~A}, 3 \mathrm{~B}$

S.W.: $1 \mathrm{~A}, 1 \mathrm{~B}, 2 \mathrm{~A}, 3 \mathrm{~A}$

\section{Financial Disclosures of all authors (for the preceding 12 months)}

Silke Walleser Autiero reports salary from Medtronic International Trading Sàrl.

Tzu-Chun Kuo reports consulting fees from PHMR, LLC.

Mihail Samnaliev reports salary from Children's Hospital Boston; consulting fees from PHMR, LLC. Rod S Taylor reports salary from the University of Exeter Medical School; consulting fees from Medtronic International Trading Sàrl.

Travis S Tierney reports salary from the Brain Institute, Nicklaus Children's Hospital, and neurosurgical consulting fees from Delray Medical Group.

Anette Schrag reports salary from the UCL Institute of Neurology; support from the National Institute for Health Research University College London Hospitals Biomedical Research Centre; consulting fees from Medtronic International Trading Sàrl.

Sharada Weir reports salary from the Centre for Addiction and Mental Health, University of Toronto; consulting fees from PHMR, LLC. 


\section{References}

1. Péchevis $M$, Clarke CE, Vieregge $P$, Khoshnood B, Deschaseaux-Voinet $C$, Berdeaux G, Ziegler M. Effects of dyskinesias in Parkinson's disease on quality of life and health-related costs: a prospective European study. Eur J Neurol 2005;12(12):956-963.

2. Quittenbaum BH, Grahn B (2004) Quality of life and pain in Parkinson's disease: a controlled cross-sectional study. Parkinsonism Relat Disord 10:129-136.

3. Riazi A, Hobart JC, Lamping DL, Fitzpatrick R, Freeman JA, Jenkinson C, Peto V, Thompson AJ (2003) Using the SF-36 measure to compare the health impact of multiple sclerosis and Parkinson's disease with normal population health profiles. J Neurol 74:710-714.

4. Schrag A, Jahanshahi M, Quinn N (2000) What contributes to quality of life in patients with Parkinson's disease? J Neurol Neurosurg Psychiatry 69:308-312.

5. Rahman S, Griffin HJ, Quinn NP (2008) Quality of life in Parkinson's disease: the relative importance of the symptoms. Mov Disord 23(10):1428-1434.

6. Valeikiene V, Ceremnych J, Alekna V, Juozulynas A (2008) Differences in WHOLQOL-100 domain scores in Parkinson's disease and Osteoarthritis. Med Sci Monit 14(4):CR221-CR227.

7. Visser M, van Rooden SM, Verbaan D, Marinus J, Stiggelbout AM, van Hilten JJ (2008) A comprehensive model of health related quality of life in Parkinson's disease. J Neurol 255(10):1580-1587.

8. Visser M, Verbaan D, van Rooden SM (2009) A longitudinal evaluation of health-related quality of life of patients with Parkinson's disease. Value Health 12(2):392-396.

9. Montel S, Bonnet A-M, Bungener C (2009) Quality of life in relation to mood, coping strategies and dyskinesia in Parkinson's disease. J Geriatr Psychiatry Neurol 22(2):95-102.

10. Findley L, Aujla M, Bain PG, Baker M, Beech C, Bowman C, Holmes J, Kingdom WK, MacMahon DG, Peto V, Playfer JR. Direct economic impact of Parkinson's disease: a research survey in the United Kingdom. Mov Disord 2003;18(10):1139-1145.

11. Findley $L$, Wood E, Lowin J, Roeder C, Bergman A, Schifflers M. The economic burden of advanced Parkinson's disease: an analysis of a UK patient dataset. J Med Econ 2011;14(1):130-9.

12. McCrone $P$, Allcock LM, Burn DJ. Predicting the cost of Parkinson's disease. Mov Disord 2007;22(6):804-12. 
13. Rodríguez-Blázquez C, Forjaz MJ, Lizán L, Paz S, Martínez-Martín P. Estimating the direct and indirect costs associated with Parkinson's disease. Expert Rev Pharmacoecon Outcomes Res 2015;15(6):889-911.

14. Lewis JD, Brensinger C. Agreement between GPRD smoking data: a survey of general practitioners and a population-based survey. Pharmacoepidemiol Drug Saf 2004;13:437441.

15. Wood L, Martinez C. The general practice research database: role in pharmacovigilance. Drug Saf 2004;27:871-881.

16. Jick H, Jick SS, Derby LE. Validation of information recorded on general practitioner based computerised data resource in the United Kingdom. BMJ 1991;302:766-768.

17. Jick H, Terris BZ, Derby LE, Jick SS. Further validation of information recorded on a general practitioner based computerized data resource in the United Kingdom. Pharmacoepidemiol Drug Saf 1992;1:347-349.

18. Hollowell J. The General Practice Research Database: quality of morbidity data. Population Trends 1997;87:36-40.

19. García Rodríguez LA, Gutthann SP. Use of the UK General Practice Research Database for pharmacoepidemiology. Br J Clin Pharmacol 1998;45(5):419-425.

20. NHS Digital, The Health and Social Care Information Centre. Hospital Episode Statistics: Hospital Outpatient Activity 2011-12 Summary report, 2012. Available online: http://content.digital.nhs.uk/catalogue/PUB09379/hosp-outp-acti-11-12-summ-reporep.pdf (Accessed: December 11, 2016).

21. Hernán MA, Logroscino G, Rodríguez LA. A prospective study of alcoholism and the risk of Parkinson's disease. J Neurol 2004;251 Suppl 7:vll14-7.

22. Hernán MA, Logroscino G, García Rodríguez LA. Nonsteroidal anti-inflammatory drugs and the incidence of Parkinson disease. Neurology 2006;66:1097-1099.

23. Becker C, Jick SS, Meier CR. Use of antihypertensives and the risk of Parkinson disease. Neurology 2008;70(16 Part 2):1438-1444.

24. Becker C, Jick SS, Meier CR. NSAID use and risk of Parkinson disease: a population-based case-control study. Eur J Neurol 2011;18(11):1336-1342.

25. Schade R, Andersohn F, Suissa S, Haverkamp W, Garbe E. Dopamine agonists and the risk of cardiac-valve regurgitation. N Engl J Med 2007;356:29-38. 
26. Horsfall L, Petersen I, Walters K, Schrag A. Time trends in incidence of Parkinson's disease diagnosis in UK primary care. J Neurol 2013;260:1351-1357.

27. Alonso A, Rodriguez LA, Logroscino G, Hernan MA. Gout and risk of Parkinson disease: a prospective study. Neurology 2007; 69: 1696-700

28. Schrag A, Horsfall L, Walters K, Noyce A, Petersen I. Prediagnostic presentations of Parkinson's disease in primary care: a case-control study. Lancet Neurol 2015;14(1):57-64.

29. Parsons LS. Reducing Bias in a Propensity Score Matched-Pair Sample Using Greedy Matching Techniques. SAS Users Group International 26 (SUGI26), Paper 214-26, 2001. (Available online: http://www2.sas.com/proceedings/sugi26/p214-26.pdf; Accessed: October 16, 2016).

30. Manca A, Austin PC. Using propensity score methods to analyse individual patient-level cost-effectiveness data from observational studies, University of York HEDG Working Paper No. 08/20, 2008. (Available online: http://www.york.ac.uk/res/herc/research/hedg/wp.htm; Accessed: October 16, 2016).

31. Onukwugha E, McRae J, Kravetz A, et al. Cost-of-illness studies: an updated review of current methods. PharmacoEconomics 2016;34:43.

32. Akobundu E, Ju J, Blatt L, Mullins CD. Cost-of-illness studies: a review of current methods. Pharmacoeconomics 2006;24:869-90.

33. Jefferson T, Demicheli V, Mugford M. Cost-of-illness studies, elementary economic evaluation in health care. 2nd Ed. London, BMJ Publishing Group, 2000, pp. 17-29.

34. Mogyorosy Z, Smith P. The main methodological issues in costing health care services: A literature review. Centre for Health Economics, University of York Working Papers, 2005.

35. NICE. Guide to the methods of technology appraisal. National Institute for Clinical Excellence (NICE), 2013.

36. Punekar YS, Shukla A, Müllerova H. COPD management costs according to the frequency of COPD exacerbations in UK primary care. Int J Chron Obstruct Pulmon Dis 2014;9:65-73.

37. Reed C, Hong J, Novick D, Lenox-Smith A, Happich M. Health care costs before and after diagnosis of depression in patients with unexplained pain: a retrospective cohort study using the United Kingdom General Practice Research Database. Clinicoecon Outcomes Res 2013;5:37-47. 
38. Drummond $M$, Jefferson T. Guidelines for authors and peer reviewers of economic submissions to the BMJ. BMJ 1996;313(7052);275-83.

39. Gulliford MC, Charlton J, Bhattarai N, Charlton C, Rudisill C. Impact and cost-effectiveness of a universal strategy to promote physical activity in primary care: population-based cohort study and Markov model. Eur J Health Econ 2014;15(4):341-51.

40. Holden SE, Jenkins-Jones S, Poole CD, Morgan CL, Coghill D, Currie CJ. The prevalence and incidence, resource use and financial costs of treating people with attention deficit/hyperactivity disorder (ADHD) in the United Kingdom (1998 to 2010). Child Adolesc Psychiatry Ment Health 2013;7:34.

41. Hong J, Reed C, Novick D, Happich M. Costs Associated With Treatment of chronic low back pain: an analysis of the UK General Practice Research Database. Spine (Phila Pa 1976) 2013;38(1):75-82.

42. Charlton J, Rudisill C, Bhattarai N, Gulliford M. Impact of deprivation on occurrence, outcomes and health care costs of people with multiple morbidity. J Health Serv Res Policy 2013;18(4):215-23.

43. Brilleman SL, Purdy S, Salisbury C, Windmeijer F, Gravelle H, Hollinghurst S. Implications of comorbidity for primary care costs in the UK: a retrospective observational study. Br J Gen Pract 2013;63(609):e274-82.

44. Adogwa O, Owens R, Karikari I, et al. Revision lumbar surgery in elderly patients with symptomatic pseudarthrosis, adjacent-segment disease, or same-level recurrent stenosis. Part 2. A cost-effectiveness analysis: clinical article. J Neurosurg Spine 2013;18(2):147-53.

45. Curtis L. Unit Costs of Health and Social Care 2013. Canterbury, Personal Social Services Research Unit, Kent, 2013.

46. Department of Health. Reference Costs 2012-13. Available online: https://www.gov.uk/government/publications/nhs-reference-costs-2012-to-2013 (Accessed: April 6, 2014).

47. NHS Digital. HRG4+ 2012/13 Reference Costs Grouper and Documentation. Available online: http://content.digital.nhs.uk/article/4698/HRG4-201213-Reference-Costs-Grouper-andDocumentation (Accessed: December 16, 2016).

48. British National Formulary (BNF). Available online: http://www.bnf.org/bnf/org 450080.htm (Accessed: September 9, 2014). 
49. Glick HA, Doshi JA, Sonnad SS, Polsky D. Economic Evaluation in Clinical Trials. (Oxford, UK: Oxford University Press), 2007.

50. Kaltenboeck A, Johnson SJ, Davis MR, et al. Direct costs and survival of medicare beneficiaries with early and advanced Parkinson's disease. Parkinsonism Relat Disord 2012;18(4):321-6.

51. Kempster PA, O'Sullivan SS, Holton JL, Revesz T, Lees AJ. Relationships between age and late progression of Parkinson's disease: a clinico-pathological study. Brain 2010;133(Pt 6):175562.

52. Tomlinson CL, Stowe R, Patel S, Rick C, Gray R, Clarke CE. Systematic review of levodopa dose equivalency reporting in Parkinson's disease. Mov Disord 2010;25(15):2649-53.

53. Deuschl G, Schade-Brittinger C, Krack P, et al. A randomized trial of deep-brain stimulation for Parkinson's disease. N Engl J Med 2006;355:896-908.

54. Alzheimer's Society. Dementia UK Update. (London, UK: Alzheimer's Society), 2014.

55. Dodel RC, Singer M, Köhne-Volland R, Szucs T, Rathay B, Scholz E, Oertel WH. The economic impact of Parkinson's disease. An estimation based on a 3-month prospective analysis. Pharmacoeconomics. 1998 Sep;14(3):299-312.

56. LePen C, Wait S, Moutard-Martin F, Dujardin M, Ziégler M. Cost of illness and disease severity in a cohort of French patients with Parkinson's disease. PharmacoEconomics 1999;16(1):59-69.

57. Spottke AE, Reuter M, Machat O, et al. Cost of illness and its predictors for Parkinson's disease in Germany. Pharmacoeconomics 2005;23(8):817-36.

58. Findley $\amalg$. The economic impact of Parkinson's disease. Parkinsonism Relat Disord. 2007;13 Suppl:S8-S12.

59. Parkinson's UK. What's the Cost of Living with Parkinson's? Available online: https://www.parkinsons.org.uk/news/whats-cost-living-parkinsons (Accessed: August 4, 2017).

60. Ishihara LS, Cheesbrough A, Brayne C, Schrag A. Estimated life expectancy of Parkinson's patients compared with the UK population. J Neurol Neurosurg Psychiatry. 2007;78(12):1304-9. 


\section{Supporting Data}

Additional Supporting Information may be found in the online version of this article at the publisher's website. 